\title{
Propagation of narrow-band-high-frequency clicks: Measured and modeled transmission loss of porpoise-like clicks in porpoise habitats
}

\author{
Stacy L. DeRuiter \\ IFREMER, Service Acoustique et Sismique, BP 70, 29280 Plouzané, France and Department of Biology, \\ Woods Hole Oceanographic Institution (WHOI), MS 50, Woods Hole, Massachusetts 02543 \\ Michael Hansen \\ Department of Biological Sciences, Zoophysiology, Aarhus University, C.F. Mфllers Allé, Building 1131, \\ DK-8000 Aarhus C, Denmark \\ Heather N. Koopman and Andrew J. Westgate \\ Department of Biology and Marine Biology, University of North Carolina Wilmington, Wilmington, North \\ Carolina 28403-3297 and Grand Manan Whale and Seabird Research Station, 24 Route 776, Grand \\ Manan, New Brunswick E5G 1A1, Canada \\ Peter L. Tyack \\ Department of Biology, Woods Hole Oceanographic Institution (WHOI), MS 50, Woods Hole, Massachusetts \\ 02543 \\ Peter T. Madsen \\ Department of Biology, Woods Hole Oceanographic Institution (WHOI), MS 50, Woods Hole, Massachusetts \\ 02543 and Department of Biological Sciences, Zoophysiology, Aarhus University, C.F. Mфllers Allé, \\ Building 1131, DK-8000 Aarhus C, Denmark
}

(Received 16 July 2009; revised 11 September 2009; accepted 25 September 2009)

\begin{abstract}
Estimating the range at which harbor porpoises can detect prey items and environmental objects is integral to understanding their biosonar. Understanding the ranges at which they can use echolocation to detect and avoid obstacles is particularly important for strategies to reduce bycatch. Transmission loss (TL) during acoustic propagation is an important determinant of those detection ranges, and it also influences animal detection functions used in passive acoustic monitoring. However, common assumptions regarding TL have rarely been tested. Here, TL of synthetic porpoise clicks was measured in porpoise habitats in Canada and Denmark, and field data were compared with spherical spreading law and ray-trace (Bellhop) model predictions. Both models matched mean observations quite well in most cases, indicating that a spherical spreading law can usually provide an accurate first-order estimate of TL for porpoise sounds in porpoise habitat. However, TL varied significantly $( \pm 10 \mathrm{~dB})$ between sites and over time in response to variability in seafloor characteristics, sound-speed profiles, and other short-timescale environmental fluctuations. Such variability should be taken into account in estimates of the ranges at which porpoises can communicate acoustically, detect echolocation targets, and be detected via passive acoustic monitoring. (C) 2010 Acoustical Society of America. [DOI: 10.1121/1.3257203]
\end{abstract}

PACS number(s): 43.80.Ka, 43.30.Es, 43.80.Lb [WWA]

Pages: $560-567$

\section{INTRODUCTION}

Harbor porpoises (Phocoena phocoena) are small toothed whales that inhabit temperate and subarctic waters of the northern hemisphere, and like all toothed whale species investigated, they use echolocation for foraging and navigation. However, little is known about the echolocation strategies of porpoises in the wild (Au, 1993; Akamatsu et al., 2005, 2007). Estimating the range at which porpoises can detect prey items and other environmental landmarks is an integral part of studies of harbor porpoise biosonar. It is also a key to understanding obstacle detection and avoidance behavior relevant to fishery bycatch reduction strategies $\mathrm{Au}$ and Jones, 1991; Kastelein et al., 2000; Mooney et al., 2004, 2007). To predict the maximum range at which an object can be detected using echolocation, one must measure or estimate click source level, minimum detectable received echo level (in noise), target strength of the prey item or other target, and propagation loss between the echolocating animal and the target. Such estimates have been published for species including harbor porpoises (Au et al., 2007; Mooney et al., 2007; Villadsgaard et al., 2007), bottlenose dolphins (Au et al., 2007), orcas (Au et al., 2004), false killer whales and Risso's dolphins (Madsen et al., 2004), and Hector's and hourglass dolphins (Kyhn et al., 2009). To estimate transmission loss (TL), all of those studies used a spherical spreading law with a frequency dependent attenuation factor. Because toothed whale echolocation clicks are generally short in duration and emitted in a narrow beam (Au, 1993), temporal overlap of surface- and bottom-reflected arrivals will be rare 
except at longer ranges in shallower habitats, and the spherical spreading assumption should hold unless significant water-column refraction occurs. However, this common assumption is not normally validated empirically ( $\mathrm{Au}, 1993$; Madsen and Wahlberg, 2007; but see Miksis-Olds and Miller, 2006; Villadsgaard et al., 2007). Testing this assumption and quantifying porpoise-habitat-specific and temporal variability in transmission loss could thus provide valuable data on the accuracy of detection-range estimates. It would also provide insight into the biophysical basis of porpoise acoustic ecology in the context of foraging, predator avoidance, and social communication.

Data on transmission loss are not only important for studies of porpoise biosonar and communication. Passive acoustic monitoring (PAM) with automatic click detection devices such as T-POD porpoise detectors (Thomsen et al., 2005) has become an increasingly common method for monitoring the presence and abundance of toothed whales, especially harbor porpoises; T-PODs have been used both to study habitat utilization patterns (Carlström, 2005; Philpott et al., 2007; Verfuss et al., 2007; Todd et al., 2009) and to quantify changes in detection rates in response to anthropogenic noise (Cox et al., 2001; Culik et al., 2001; Koschinski et al., 2003; Carstensen et al., 2006; Leeney et al., 2007; Carlström et al., 2009). PAM provides data on the time and intensity of detected sounds, not the spatial abundance of animals. To determine the probability of call detection as a function of range and to convert detection rates into estimates of density and abundance, current methods rely on either (1) model predictions of TL coupled with a conversion factor relating click trains detected to the number of individuals present (Stafford et al., 2007; Zimmer et al., 2008) or (2) distance sampling techniques requiring calibration data, for example, PAM detections of sounds produced at known times by animals at known positions (Marques et al., 2009). In the absence of such experimental data collected under equivalent transmission loss conditions, testing assumptions about transmission loss is critical for correct interpretation of passive acoustic monitoring data.

Potential variability in TL in response to environmental fluctuations is likely a significant source of error in PAM density estimates just as it is for biosonar detection range estimates, and since that variability is not generally taken into account in model-based TL estimates, field measurements of habitat-specific and temporal variations in TL are critical.

Here, we experimentally test the hypothesis that a spherical spreading law with attenuation can accurately predict the transmission loss of harbor porpoise-like clicks in porpoise habitats, comparing field measurements of the transmission loss of porpoise-like clicks in porpoise habitats in Canada and Denmark with values predicted by a spherical spreading law with attenuation and by a ray-trace acoustic propagation model (Bellhop). In addition, we outline temporal and spatial variability in TL at our experimental sites and discuss implications for passive acoustic monitoring and the acoustic ecology of porpoises.
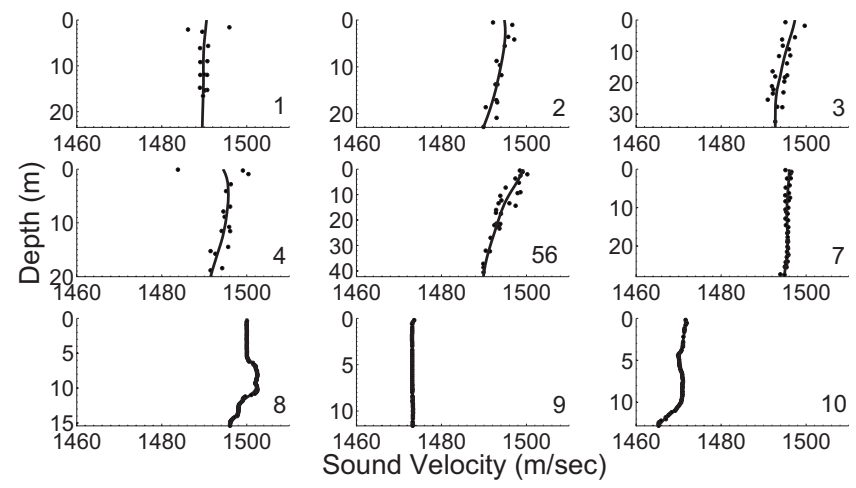

FIG. 1. Sound-speed profiles at the experimental sites. The black dots indicate raw CTD data, and the solid black lines indicate the smoothed soundspeed profiles used for acoustic modeling. Experiment numbers are indicated in the lower right corner of each plot.

\section{METHODS}

\section{A. Description of field sites}

Field measurements of transmission loss of porpoiselike clicks were made in two areas: near Grand Manan, New Brunswick, Canada $\left(44.74^{\circ}-44.79^{\circ} \mathrm{N}, 66.72^{\circ}-66.77^{\circ} \mathrm{W}\right)$ and in Aarhus Bay near Aarhus, Denmark $\left(56.15^{\circ} \mathrm{N}\right.$, $10.3^{\circ} \mathrm{E}$ ). Both locations are characterized by high densities of harbor porpoises and represent important habitat. The Grand Manan experiments (1-7) were carried out at six sites along the northeast coast of the island between 8-13 August 2006. In Aarhus Bay, measurements were made at the same site in the middle of the bay on 5 September 2006, 29 November 2006, and 16 April 2007 (experiments 8-10).

CTD measurements were taken in conjunction with each experiment to determine a sound-speed profile for each site, and echosounder measurements were used to characterize the bathymetry at each site. Figure 1 shows the sound-speed profiles calculated from the CTD (Conductivity, Temperature, Depth) data for experiments 1-10. The sound-speed profiles for experiments 1, 7, and 9 show nearly isovelocity water columns with minimal variation in sound speed with depth. In contrast, experiment sites 2-6 and 10 have downwardrefracting sound-speed profiles, and site 8 has a lowervelocity sound channel of about 6-12-m depth. All Grand Manan sites had relatively flat bathymetry, with a maximum downward slope of about 3 deg at sites 5 and 6 . The sites in Aarhus Bay had flat bottoms with water depths of 15, 12, and $13 \mathrm{~m}$ for experiments $8-10$, respectively.

While we did not measure bottom properties at our sites, relevant data are available from several sources. Paskevich $e t$ al. (2001) and Poppe et al. (2005) provided sediment grainsize data for sites about $15 \mathrm{~km}$ from the experimental sites, but further from the coast of Grand Manan; they found mainly silty clay, occasionally with a small amount of sand or shells. The sediments in Aarhus Bay are also mainly silty clay or sandy clay (Lund-Hansen et al., 2002; Røy et al., 2005).

\section{B. Acoustic data collection and processing}

The experimental setup for transmission loss measurements required two platforms: one to transmit the signals 
from a fixed location, and one to receive the signals at a variety of ranges. One boat was anchored or tied up to a fixed object and was attached to the other by a line. The transducer was deployed over the side of the transmit boat, continuously transmitting synthetic porpoise clicks. The length of the line between boats was adjusted to position the receiving boat at stations $5,10,25,50,100,150$ (experiments 9 and 10 only), and $200 \mathrm{~m}$ (experiments 1-7 only) from the transmitter. Source-receiver ranges were verified by radar and range finder when possible. At each station, the receiving boat made $1-5$-min recordings of the transmitted signal using two hydrophones deployed at 3- and 5-m depths.

The transmitted signal in all experiments was a series of synthetic porpoise clicks with acoustic properties very similar to those of real clicks. We chose to use synthetic clicks rather than real ones for consistency and to avoid the difficulty of selecting a single click from a single animal to designate as typical. Each synthetic click consisted of 11 (experiments 1-8) or 15 (experiments 9 and 10) equalamplitude cycles of a $135-\mathrm{kHz}$ tone, with a $10-\mathrm{ms}$ click interval. The duration of each synthetic click was about $82 \mu \mathrm{s}$ (11 cycles) or $111 \mu \mathrm{s}$ (15 cycles). Thus, the duration, frequency, and measured bandwidth (about $7 \mathrm{kHz}$ ) of the synthetic clicks were similar to the duration (about $75-250 \mu \mathrm{s})$, peak frequency $(120-142 \mathrm{kHz})$, and bandwidth $(6-26 \mathrm{kHz})$ of typical harbor porpoise echolocation clicks (Au, 1993; Au et al., 1999; Villadsgaard et al., 2007). We used an Agilent 33220A signal generator (Agilent Technologies, Santa Clara, CA) to produce the clicks at a peak-peak amplitude of $1 \mathrm{~V}$, amplified the signal by $46 \mathrm{~dB}$ using a custom-built amplifier (courtesy of Niels U. Kristiansen) for a total amplitude of about $200 \mathrm{~V}$ peak-peak, and transmitted them into the water with a Brüel \& Kjær 8105 spherical hydrophone (Brïel \& Kjær Sound \& Vibration Measurement A/S, Nærum, Denmark; transmit sensitivity at $135 \mathrm{kHz}$ of $138 \mathrm{~dB}$ relative to $1 \mu \mathrm{Pa} / \mathrm{V}$ at $1 \mathrm{~m}$ ) deployed at either 5-m depth (experiments 1-7 and 10) or 3-m depth (experiments 8 and 9). Although porpoises produce directional echolocation clicks with a $-3-\mathrm{dB}$ beam width of about $16 \mathrm{deg}$ (Au et al., 1999), we chose to use an omnidirectional transducer to avoid the problem of ensuring that the receiving hydrophones were on the acoustic axis of a directional transducer. The measured source level of the transmissions was $184 \mathrm{~dB}$ re $1-\mu \mathrm{Pa}$ peak-peak at $1 \mathrm{~m}$, which is within the expected range for wild harbor porpoise echolocation clicks [178-205 $\mathrm{dB}$ re $1-\mu \mathrm{Pa}$ peak-peak at $1 \mathrm{~m}$ (Villadsgaard et al., 2007)]. We used two types of hydrophones as receivers: a Reson TC4034 hydrophone (Reson, Slangerup, Denmark) with a receiving sensitivity of $-220 \mathrm{~dB}$ relative to $1 \mathrm{~V} / \mu \mathrm{Pa}$ at 135 $\mathrm{kHz}$ and a Reson 4014 hydrophone with a receiving sensitivity of $-186 \mathrm{~dB}$ relative to $1 \mathrm{~V} / \mu \mathrm{Pa}$ at $135 \mathrm{kHz}$.

For the Grand Manan experiments (Nos. 1-7), at each station, 1-5-min sound recordings of the signal were collected with hydrophones deployed at 3- and 5-m depths. The signal at 3-m depth was recorded on a Reson TC4034 hydrophone, amplified either 40 or $60 \mathrm{~dB}$ with a custom-built amplifier, and band-pass filtered with an analog filter between $1.7 \mathrm{kHz}$ (one pole) and $160 \mathrm{kHz}$ (four poles). The signal at 5-m depth was recorded on a Reson TC4014 hydrophone, amplified $32 \mathrm{~dB}$ with an etec amplifier (etec, Frederiksvaerk, Denmark), and high-pass filtered with an analog filter (one pole) at $1 \mathrm{kHz}$. All signals from the hydrophones were digitized using a 333-kHz sampling rate (16-bit resolution) on a Wavebook 516E analog to digital converter (IOtech, Cleveland, Ohio), and the resulting files were saved on a laptop computer. In order to maximize resolution in the recordings, amplification on the 3-m hydrophone was varied between 40 and $60 \mathrm{~dB}$, and the clip level of the digital recordings was varied between $0.2-$ and $10-\mathrm{V}$ peak-peak.

The recording setup was slightly different for the Danish experiments (experiments 8-10). At each station, 1-5-min sound recordings of the signal were collected using hydrophones deployed at 3- and 5-m depths. Both channels were recorded on Reson TC4034 hydrophones amplified either 40 or $60 \mathrm{~dB}$. Signals from the hydrophones were filtered with an analog band-pass filter between $1 \mathrm{kHz}$ (one pole) and 200 $\mathrm{kHz}$ (four poles) and digitized at 500-Hz sampling rate (12bit resolution) on an ADLINK analog-digital converter (ADLINK Technology Inc., Taipei, Taiwan); the resulting data files were saved to a laptop computer. The peak-peak clip level of the digital recordings was $10 \mathrm{~V}$ (experiment 8) or $4 \mathrm{~V}$ (experiments 9 and 10).

The recordings from each station were band-pass filtered between 100 and $160 \mathrm{kHz}$ with an eighth order Butterworth filter in ADOBE AUDITION (Adobe, San Jose, CA). Using custom-written scripts in MATLAB (The MathWorks, Natick, MA), we applied an envelope-based click detector to extract 100 clicks from each file and calculate the peak-peak received level (RL) of each click. The click detection routine outputs the peak RL of the highest amplitude acoustic arrival only (and not the combined level of several multipath arrivals) as long as the delay in arrival time between the arrivals is greater than about $100 \mu \mathrm{s}$ and thus the arrivals do not overlap in time. We subtracted the RLs from the measured transmitter source level, $184 \mathrm{~dB}$ re $1-\mu \mathrm{Pa}$ peak-peak, to obtain the transmission loss of each click, recording the observed transmission loss of 100 clicks at each station for comparison with model predictions. For experiment 10, we also carried out a pulse-compression analysis (crosscorrelation of the data waveform with the theoretical transmitted signal) to examine arrival structure as a function of time.

\section{Transmission loss predictions \\ 1. Spreading law calculations}

We first applied a spherical spreading law [TL $=20 \log _{10}($ range $\left.)\right]$ to predict transmission loss. At high frequencies such as the $135 \mathrm{kHz}$ considered in these experiments, absorption also contributes significantly to the transmission loss, so we included an additional absorption loss of $0.04 \mathrm{~dB} / \mathrm{m}$ [representative of values calculated according to Francois and Garrison (1982a, 1982b) for actual environmental conditions at the study sites] in the transmission loss calculation. We expected this spreading law/attenuation TL approximation to be accurate only in areas where the sound speed was relatively homogeneous and the sound did not 
interact with the bottom or the sea surface before arriving at the receiver. Because the transmitted signal was very short, one would predict those conditions to hold unless receiver depth was very shallow or source-receiver range was large (Madsen and Wahlberg, 2007).

\section{Bellhop acoustic propagation model}

We also applied an acoustic propagation model, which can take into account the sound-speed profile, bathymetry, and bottom properties as well as multipath acoustic propagation, to predict transmission loss at each experiment site. Because of the high frequency of the sound source used in these experiments, we chose Bellhop, a ray-tracing model, for these predictions (Porter and Bucker, 1987). We used the ACTUP MATLAB front-end (Amos Maggi and Alec Duncan, available at http://www.cmst.curtin.edu.au/products/ actoolbox/, last viewed 6/30/09) to interface with Bellhop. We did not gather data on the bottom properties at each site, but as noted earlier, published data indicate that the experimental sites are dominated by silty clay sediments (Paskevich et al., 2001; Lund-Hansen et al., 2002; Poppe et al., 2005; Røy et al., 2005). In this sediment type, the ratio of sound speed in the surface sediments to sound speed in the water overlying the sediments is generally about 0.984 (Jackson and Richardson, 2007). We combined that ratio with the sound speed at the base of the sound-speed profile to calculate a sediment sound speed for each experimental site; we then used Hamilton's (1978) equations to estimate sediment density. Finally, following Jackson and Richardson (2007) for silty clay sediments, we estimated bottom attenuation in the sediments to be about $0.45 \mathrm{~dB}$ per wavelength. The aforementioned sound speed, density, and attenuation values defined an isovelocity bottom layer for each of the experiment sites. We carried out Bellhop model runs to determine the incoherent transmission loss and arrival-time delay of each arrival at the appropriate receiver depth/range locations at each site. Using those results, we calculated a transmission loss estimate for each combination of experiment sites and receiver stations. To match our transmission loss measurements, this estimate included the transmission loss of the highest-amplitude arrival at the receiver (generally the first, direct arrival), summed with the amplitudes of any other arrivals that overlapped temporally with the highest-amplitude arrival. In practice, no temporal overlap of modeled arrivals occurred, so our Bellhop TL estimate was based on the amplitude of a single arrival.

\section{Comparison of TL data and predictions}

We used two measures to compare our observed TL with the spreading law and Bellhop model predictions. First, we simply calculated the error of each model (for each station in each experiment) by subtracting the average observed TL from the predicted TL. Second, we calculated a rootmean-squared-error (RMSE) value for each experiment and for the set of ten experiments according to RMSE $=\sqrt{ }\left(\right.$ mean $\left.\left(\mathrm{TL}_{\text {predicted }}-\mathrm{TL}_{\text {data }}\right)^{2}\right)$, using the mean observed TL at each site and range. For RMSE calculations, the error

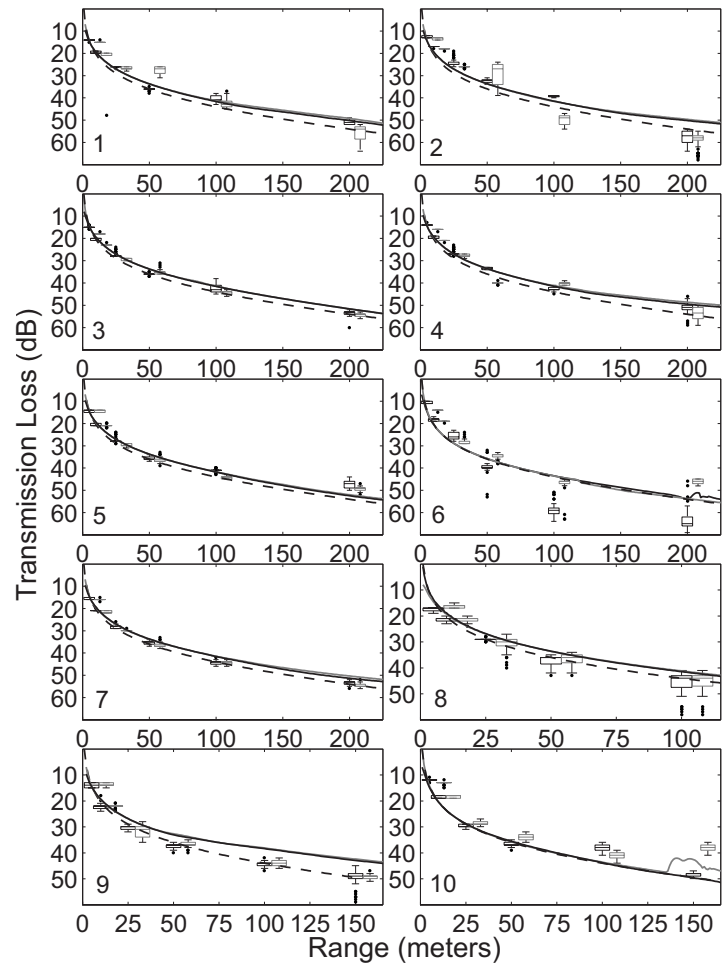

FIG. 2. Measured and modeled transmission losses as a function of range (experiment numbers are indicated in the lower left corner of each panel). Measured received levels are presented as box-and-whisker plots (black boxes show data collected at 3-m receiver depth, and gray boxes show data collected at 5-m receiver depth). The boxes extend to the upper and lower quartiles of observed field TL values, with a horizontal line inside each box indicating the median. The whiskers extend to the largest and smallest observed values in the time bin, up to 1.5 times the interquartile range; values outside this range are plotted as black dots. For readability, the 5-m receiver depth data are offset slightly along the $x$ axis (to higher range values), but were collected at the same time and range as the 3-m data. The dashed black lines show the transmission loss predicted by a spherical spreading model with attenuation. The black and gray traces show transmission loss predicted by the Bellhop acoustic propagation model (black for 3-m receiver depth and gray for 5-m receiver depth).

values in decibels $\left(\mathrm{TL}_{\text {predicted }}-\mathrm{TL}_{\mathrm{data}}\right)$ were converted to linear units (amplitude), and then the resulting RMSE values were converted back into decibels.

\section{RESULTS}

Figure 2 compares measured and modeled transmission losses for experiments 1-10. For most of our experiments (1-4 and 7-9), both Bellhop model output and data inspection confirmed that transmission loss increased with range, the first arrival at each receiver had the highest peak-peak amplitude, and it did not overlap in time with other arrivals. For experiments 5, 6, and 10, however, we found that the highest-amplitude recorded click was sometimes not the first arrival, but a later arrival that appeared to be composed of several overlapping arrivals. We observed this phenomenon at source-receiver ranges as short as $10 \mathrm{~m}$ in experiment 5 , $25 \mathrm{~m}$ in experiment 6 , and $50 \mathrm{~m}$ in experiment 10 . As an example, Fig. 3 shows data from experiment 10 for a receiver depth of $3 \mathrm{~m}$ and a source-receiver range of $50 \mathrm{~m}$. The figure includes the waveforms of received arrivals from 100 clicks as well as the results of the pulse-compression analy- 


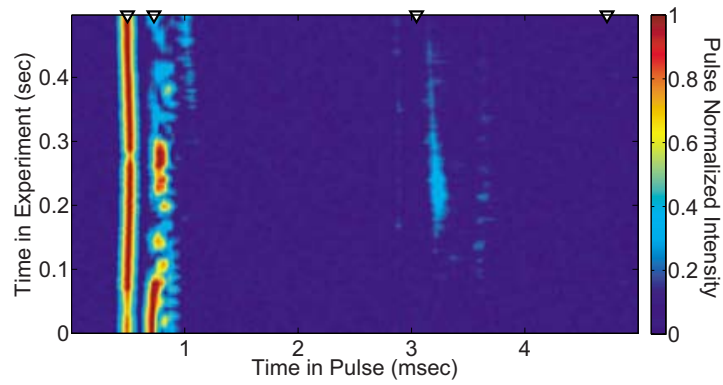

FIG. 3. (Color online) This figure contains data from experiment 10 for a receiver depth of $3 \mathrm{~m}$ and a source-receiver range of $50 \mathrm{~m}$. Time is on the $x$ axis; 0 points are arbitrary with respect to pulse transmission and reception, but are $10 \mathrm{~ms}$ apart to match the inter-click interval of transmissions. Every horizontal line shows data for one pulse (100 consecutive pulses, received over $0.5 \mathrm{~s}$, are plotted). Color indicates pulse intensity resulting from pulsecompression analysis. Arrows on the upper $x$ axis indicate Bellhop-predicted arrival times for the first (direct), second (surface-reflected), third (bottomreflected), and fourth (bottom then surface-reflected) acoustic arrivals.

sis, indicating that the largest peak in the data waveform is actually composed of several overlapping arrivals. We also noted that, in experiments 6 and 10, transmission loss did not increase as smoothly with range as in the other experiments.

Figure 4 summarizes our results regarding the relative accuracy of the spreading law and Bellhop TL predictions. Figure 4 (top panel), which plots the error of both types of predicted TL as a function of source-receiver range, shows that the prediction error did tend to increase with range. However, the error points remain relatively evenly scattered around zero at all ranges, indicating that neither model has a tendency to consistently over- or under-estimate TL as range increases. Error is plotted separately for each experiment in the middle panel of Fig. 4, and the bottom panel shows the RMSE for each experiment. The two plots show that both models predicted TL quite accurately (errors not exceeding 6 $\mathrm{dB}$, RMSE less than $3 \mathrm{~dB}$ ) for experiments 3 and 7-9 and somewhat accurately for experiments 1,2 , and 4 (errors not exceeding $10 \mathrm{~dB}$, RMSE less than $5 \mathrm{~dB}$ ). They both performed poorly for experiment 6 , though the spreading law
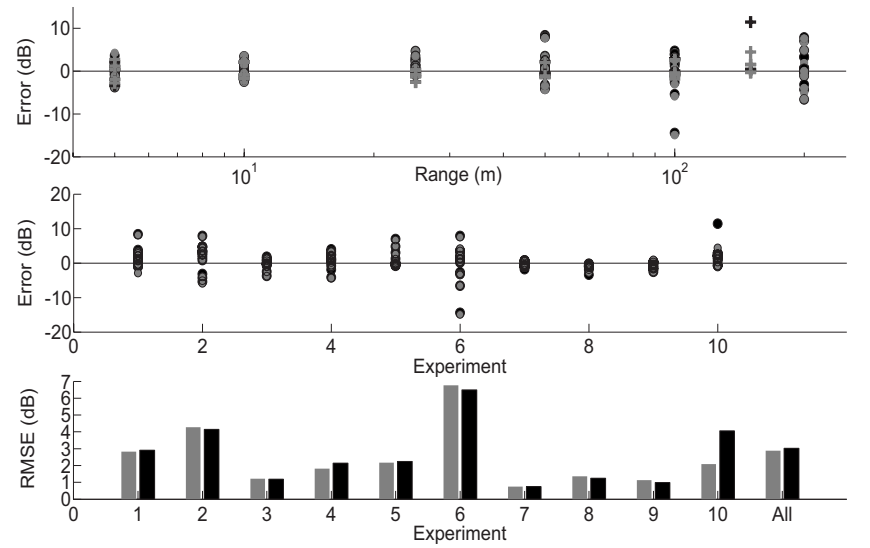

FIG. 4. Error in model predictions of mean transmission loss as a function of range and experiment. Gray symbols indicate Bellhop model error, and black indicates error by the spherical spreading law with attenuation. In the top panel, round symbols represent data from Grand Manan, while crosses are data from Denmark. In the top two panels, each data point gives the error for one source-receiver range in one experiment; in the bottom panel, bars indicate the RMSE for each experiment. model performed somewhat better than the Bellhop model. The spreading law also performed well for experiment 5, where the Bellhop model performed less well. However, for experiment 10, the Bellhop model performed accurately while the spreading law did not. According to Fig. 4(C), the RMSE for the whole set of ten experiments was between 3 and $4 \mathrm{~dB}$ for both the spreading law prediction and the Bellhop model, with the spreading law predictions performing slightly better than the Bellhop model predictions.

\section{DISCUSSION}

In this paper, we have compared ray-trace (Bellhop) model predictions of transmission loss with a simple spherical spreading law with attenuation, which is commonly applied in predictions of transmission loss related to marine mammal echolocation and communication (Au, 1993; Madsen and Wahlberg, 2007). Both models performed quite well on average, with the possible exceptions of experiments 5 and 6 , where the environment was probably not adequately characterized (see Sec. IV E). The spreading law was able to predict TL with an average error of just over $3 \mathrm{~dB}$ at sourcereceiver ranges up to $200 \mathrm{~m}$, with less error within 50-m range (Fig. 4). We quantified the level of only the highestamplitude arrival at each station, which rarely interacted with the surface or bottom and usually underwent minimal refraction. Thus, most of the assumptions underlying the spreading law were upheld and its good performance was not surprising.

One might argue that surface and bottom interacting propagation paths are unlikely ever to influence the transmission loss of clicks made by porpoises because, unlike the transducer used in our experiments, porpoises produce highly directional clicks with a $-3-\mathrm{dB}$ beam width of about $16 \mathrm{deg}$ in the vertical plane (Au et al., 1999). Given this narrow beam and assuming that porpoises always echolocate directly toward targets in the water column, direct-path propagation likely dominates. However, this argument does not hold for PAM detections, for other sound recordings, or for cases in which the porpoise directs its echolocation beam at an angle toward the surface or bottom rather than directly at a potential target.

\section{A. Effects of water-column refraction and boundary interactions}

In some particular cases, the spreading law may not perform well, while Bellhop does better; experiment 10 is an example. There, the spreading law prediction failed due to the presence of a sound channel at about 5-m depth (Fig. 1); multiple ray paths passed through a focus near the receiver at 5-m depth and 150-m range (Fig. 5), significantly reducing the transmission loss at that location. In addition, the most powerful arrivals were not always the first, direct arrivals (Fig. 3). The spreading law model cannot be relied upon in such cases, where surface/bottom interactions and/or refraction in the water column significantly affect transmission loss.

The Bellhop model output also underestimated TL at 150 -m range somewhat for experiment 10; given the obser- 


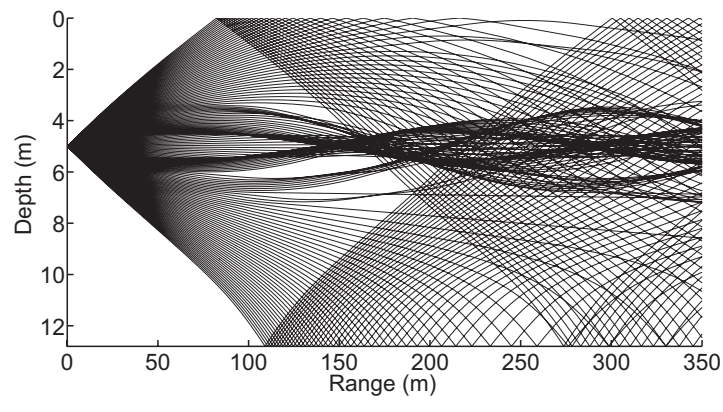

FIG. 5. Bellhop ray-trace output for the experiment 10 site. For clarity, only rays with launch angles between $\pm 20 \mathrm{deg}$ from the horizontal are shown. Some rays pass through a focus at about 5-m depth and 150-m range.

vation that the amplitude and timing of the surface-reflected arrival were rather variable and sometimes seemed to comprise several arrivals (Fig. 3), it seems possible that interactions with surface waves may explain these results (Tindle et al., 2009). We did not measure surface waves or related environmental parameters in the field and did not include them in our model.

\section{B. Implications for passive acoustic monitoring}

Previous work has shown that click source levels of free-ranging porpoises average $191 \mathrm{~dB}$ re $1-\mu \mathrm{Pa}$ peak-topeak at $1 \mathrm{~m}$ (Villadsgaard et al., 2007), and that T-POD porpoise detectors can detect porpoise clicks at levels as low as 123-132 $\mathrm{dB}$ re 1- $\mu \mathrm{Pa}$ peak-to-peak (Kyhn et al., 2008). Thus, T-PODs may detect on-axis porpoise clicks as long as $\mathrm{TL}$ is less than about $68 \mathrm{~dB}[28 \mathrm{~dB}$ for off-axis clicks since their source levels are $40 \mathrm{~dB}$ lower (Hansen et al., 2008)]. TL of this order is within or slightly exceeds the values considered in this study (measured TL first exceeded $28 \mathrm{~dB}$ at $25-$ or $50-\mathrm{m}$ range and did not exceed $68 \mathrm{~dB}$ at maximum ranges of 150-200 m). Our results can thus be used to approximate the errors that would result from use of a spreading law-based model of transmission loss in T-POD detection range estimates for areas similar to our study sites. Such errors should be relatively low on average for off-axis clicks detected at ranges of $50 \mathrm{~m}$ or less, but would probably be greater for on-axis clicks that are likely to be detected at greater ranges (Fig. 4).

Specifically, the variability in TL as a function of depth discussed in Sec. IV A has implications for passive acoustic monitoring since it results in detection probabilities and distances that vary with animal depth and detector depth. Assuming that spherical spreading with attenuation accurately estimates transmission loss, one would expect a T-POD to detect porpoises at ranges of up to about $700 \mathrm{~m}$. However, in conditions like those at the experiment 10 site, a T-POD in the sound channel would actually be able to detect porpoises in the sound channel at ranges of up to about $1200 \mathrm{~m}$ (calculated using Bellhop output for the experiment 10 site). If not accounted for, variability of this magnitude could easily result in very large errors in estimates of animal density. This effect may be particularly important to consider when comparing seasonal trends in animal detections at a given location since the presence of a sound duct during part of the year could lead to the erroneous conclusion that more ani- mals are present during that period compared to periods without a sound duct. Therefore, variability in TL as a function of depth and time should be considered when selecting detector deployment depths and reviewing passive acoustic monitoring data.

\section{Implications for porpoise biosonar and communication ranges}

The results of this study should be relevant to estimation of porpoise communication and echolocation detection ranges as long as our source-receiver ranges match the distances over which porpoises actually communicate and echolocate. Direct observations of such distances have not been made, but they can be estimated. Consider a porpoise producing echolocation clicks with source levels of $191 \mathrm{~dB}$ re $1-\mu \mathrm{Pa}$ peak-to-peak at $1 \mathrm{~m}$ (Villadsgaard et al., 2007), equivalent to an energy flux density of $140 \mathrm{~dB}$ re $1 \mu \mathrm{Pa}^{2} \mathrm{~s}$ (Kastelein et al., 1999). Assume that the porpoise echolocates on a herring with a target strength of $-37 \mathrm{~dB}$ (Ona, 2003), with a returning echo detection threshold of about $44 \mathrm{~dB}$ re $1 \mu \mathrm{Pa}^{2} \mathrm{~s}$ (Au et al., 2007). On average, echoes with one-way transmission loss of $29.5 \mathrm{~dB}$ or less would be detectable to the porpoise $[\mathrm{TL}=(140-44+(-37)) / 2$ $=29.5 \mathrm{~dB}$ ]. Our observed TL first exceeded $29.5 \mathrm{~dB}$ at ranges of 25-50 m (Fig. 2). For a similar calculation of communication call detection ranges, assume that the threshold is as above, and that communication click source levels average about $180 \mathrm{~dB}$ re $1-\mu \mathrm{Pa}$ peak-to-peak at $1 \mathrm{~m}$ (Clausen et al., 2008), equivalent to $129 \mathrm{~dB}$ re $1 \mu \mathrm{Pa}^{2} \mathrm{~s}$ (Kastelein et al., 1999). Communication sounds with TL of no more than $85 \mathrm{~dB}$ would then be detectable to conspecifics assuming that both transmitter and receiver are oriented toward one another (Hansen et al., 2008). $85 \mathrm{~dB}$ is much higher than the largest TL value we observed (61 $\mathrm{dB}$ at ranges up to $200 \mathrm{~m}$ ). Even that value could lead to an underestimate of communication range if the passive detection threshold is lower than the echo detection threshold, or if wild porpoise communication click source levels are higher than those measured in captivity.

While the spherical spreading law will in many cases provide a good estimate of the active space of porpoise clicks, experiment 10 illustrates that refraction in the water column can strongly affect transmission loss in some cases. Porpoises may be able to exploit such sound channels to increase the range at which they can detect prey or other targets with their echolocation or to increase the active space of their communication calls. For example, assuming that spherical spreading with attenuation applies and that communication calls remain detectable until TL exceeds $85 \mathrm{~dB}$ (see above calculations), the predicted maximum active space of an on-axis porpoise communication call would be about 700 $\mathrm{m}(100 \mathrm{~m}$ for an off-axis call with a source level $40 \mathrm{~dB}$ lower). By taking advantage of a sound channel like the one at the experiment 10 site, porpoises could significantly increase their maximum active space to $1.1 \mathrm{~km}$ for an on-axis call (187 $\mathrm{m}$ for an off-axis call, both calculated using Bellhop output for the experiment 10 site). Future studies could test the hypothesis that porpoises exploit sound channels by 
looking for a relationship between sound-speed profiles and the depth distribution of porpoise when they are calling and receiving acoustic signals, preferably using data from acoustic and depth-recording tags.

\section{Temporal variability}

While the modeling approaches we used predicted measured TL with relatively low error when results were averaged over time and space, variability in measured TL was high $( \pm 10 \mathrm{~dB})$ over timescales of about $1 \mathrm{~s}$ (Figs. 2 and 3), indicating that short-timescale environmental variability can strongly influence the TL of individual porpoise clicks. Variability of this magnitude on similar timescales has been previously observed in several studies and attributed to reflection of underwater sound from surface waves (Tindle et al., 2009) or the presence of a steep thermocline (where the speed of sound changed by about $4 \mathrm{~m} / \mathrm{s}$ per meter of depth) (Wilson et al., 1994). However, because our data set contains mostly direct (rather than surface-reflected) arrivals, and the sound-speed profiles at our study sites did not seem to vary rapidly with depth, neither of those sources of variability seem a likely explanation for the short-timescale variability in our results. This variability is, however, similar to that observed in TL measurements in manatee habitats (MiksisOlds and Miller, 2006).

Temporal variability in TL, like the effects discussed in Sec. IV A-B, has potential to strongly affect density estimates calculated from passive acoustic monitoring data. If possible, this variability should be quantified at PAM sites, and sites with lower variability should be selected for detector placement.

\section{E. Sources of error in the data set}

We would not necessarily expect a perfect match between our data and models due to several potential sources of error. First, we estimate that error in the source-receiver range measurements could have been as much as $10 \%$ (especially at longer ranges) due to the effects of wind, currents, and tide on the boats. Second, tidal action (especially at the Grand Manan sites) may have caused the hydrophones to hang slightly obliquely, causing errors in the nominal source and receiver depths.

Predictions from both the spherical spreading law and the Bellhop model were less accurate for experiments 5 and 6 , especially at longer ranges. We suspect that the environment model we used as Bellhop input was incomplete especially for the experiment 5 and 6 sites, as the area around the site contains boulders and a rocky ledge or outcropping, features that were not adequately characterized for inclusion in the environmental model.

\section{CONCLUSIONS}

On average, for most of the cases we considered, spherical spreading with attenuation provided relatively accurate estimates of transmission loss of synthetic porpoise clicks in natural porpoise habitats. Both of our modeling approaches were able to predict transmission loss with overall RMSE of less than about $4 \mathrm{~dB}$, and in half of the study sites with errors of less than $2 \mathrm{~dB}$. However, there was considerable variability in TL around the average value. Characterization of this variability is important before using animal sounds to estimate density and may also provide insight into porpoise acoustic ecology. The cases where spherical spreading failed to predict TL accurately involved situations where the dominant acoustic arrival was strongly affected by surface reflection or refraction in the water column. The existence of those conditions depends on site-specific source-receiver geometry, bathymetry, sediment properties, and sound-speed profile, so spherical spreading may not accurately describe transmission loss in porpoise habitats that differ significantly from the sites considered here. When adequate data on the acoustic environment are available, a more detailed model such as Bellhop can be a useful tool to assess the effects of environmental conditions on transmission loss at a particular site.

\section{ACKNOWLEDGMENTS}

We are very grateful to everyone at the Grand Manan Whale and Seabird Research Station for their advice and assistance during data collection in Canada, especially Sarah Wong, Marla Bojarski, and Hillary Lane. We also thank the crew of RV Genetica, Aarhus University, Denmark, for their help in collecting the Danish field data. Ying-Tsong Lin, James Lynch, and Arthur Newhall provided advice related to data interpretation and acoustic propagation modeling, and Ying-Tsong Lin also provided a MATLAB script used as the basis of the pulse-compression analysis. Regina CampbellMalone, Line Kyhn, Xavier Lurton, and Jakob Tougaard provided helpful comments. Field data collection was partially supported by a Student Research Award from the WHOI Ocean Life Institute (Grant No. 25051351). P.T.M. and M.H. were funded by Steno and frame grants from the Danish Natural Science Foundation.

Akamatsu, T., Teilmann, J., Miller, L. A., Tougaard, J., Dietz, R., Wang, D., Wang, K. X., Siebert, U., and Naito, Y. (2007). "Comparison of echolocation behaviour between coastal and riverine porpoises," Deep-Sea Res., Part II 54, 290-297.

Akamatsu, T., Wang, D., Wang, K. X., and Naito, Y. (2005). "Biosonar behaviour of free-ranging porpoises," Proc. R. Soc. London, Ser. B 272, 797-801.

Au, W. W. L. (1993). The Sonar of Dolphins (Springer-Verlag, New York). Au, W. W. L., Benoit-Bird, K. J., and Kastelein, R. A. (2007). "Modeling the detection range of fish by echolocating bottlenose dolphins and harbor porpoises," J. Acoust. Soc. Am. 121, 3954-3962.

Au, W. W. L., Ford, J. K. B., Horne, J. K., and Allman, K. A. N. (2004). "Echolocation signals of free-ranging killer whales (Orcinus orca) and modeling of foraging for chinook salmon (Oncorhynchus tshawytscha)," J. Acoust. Soc. Am. 115, 901-909.

Au, W. W. L., and Jones, L. (1991). "Acoustic reflectivity of netsImplications concerning incidental take of dolphins," Marine Mammal Sci. 7, 258-273.

Au, W. W. L., Kastelein, R. A., Rippe, T., and Schooneman, N. M. (1999). "Transmission beam pattern and echolocation signals of a harbor porpoise (Phocoena phocoena)," J. Acoust. Soc. Am. 106, 3699-3705.

Carlström, J. (2005). "Diel variation in echolocation behavior of wild harbor porpoises," Marine Mammal Sci. 21, 1-12.

Carlström, J., Berggren, P., and Tregenza, N. J. C. (2009). "Spatial and temporal impact of pingers on porpoises," Can. J. Fish. Aquat. Sci. 66, $72-82$.

Carstensen, J., Henriksen, O. D., and Teilmann, J. (2006). "Impacts of offshore wind farm construction on harbour porpoises: Acoustic monitoring of echolocation activity using porpoise detectors (T-PODs)," Mar. Ecol.: Prog. Ser. 321, 295-308. 
Clausen, K. T., Madsen, P. T., and Wahlberg, M. (2010). "Click communication in harbour porpoises, (Phocoena phocoena)," Bioacoustics (in press).

Cox, T. M., Read, A. J., Solow, A., and Tregenza, N. (2001). "Will harbour porpoises (Phocoena phocoena) habituate to pingers?," J. Cetacean Res. Manage. 3, 81-86.

Culik, B. M., Koschinski, S., Tregenza, N., and Ellis, G. M. (2001). "Reactions of harbor porpoises Phocoena phocoena and herring Clupea harengus to acoustic alarms," Mar. Ecol.: Prog. Ser. 211, 255-260.

Francois, R. E., and Garrison, G. R. (1982a). "Sound absorption based on ocean measurements: Part I: Pure water and magnesium sulfate contributions," J. Acoust. Soc. Am. 72, 896-907.

Francois, R. E., and Garrison, G. R. (1982b). "Sound absorption based on ocean measurements: Part II: Boric acid contribution and equation for total absorption," J. Acoust. Soc. Am. 72, 1879-1890.

Hamilton, E. L. (1978). "Sound velocity-density relations in sea-floor sediments and rocks," J. Acoust. Soc. Am. 63, 366-377.

Hansen, M., Wahlberg, M., and Madsen, P. T. (2008). "Low-frequency components in harbor porpoise (Phocoena phocoena) clicks: Communication signal, by-products, or artifacts?," J. Acoust. Soc. Am. 124, 4059-4068.

Jackson, D. R., and Richardson, M. D. (2007). High-Frequency Seafloor Acoustics (Springer Science+Business Media L.L.C., New York).

Kastelein, R. A., Au, W. W. L., and De Haan, D. (2000). "Detection distances of bottom-set gillnets by harbour porpoises (Phocoena phocoena) and bottlenose dolphins (Tursiops truncatus)," Mar. Environ. Res. 49, 359-375.

Kastelein, R. A., Au, W. W. L., Rippe, H. T., and Schooneman, N. M. (1999). "Target detection by an echolocating harbor porpoise (Phocoena phocoena)," J. Acoust. Soc. Am. 105, 2493-2498.

Koschinski, S., Culik, B. M., Henriksen, O. D., Tregenza, N., Ellis, G., Jansen, C., and Kathe, G. (2003). "Behavioural reactions of free-ranging porpoises and seals to the noise of a simulated $2 \mathrm{MW}$ windpower generator," Mar. Ecol.: Prog. Ser. 265, 263-273.

Kyhn, L. A., Tougaard, J., Jensen, F., Wahlberg, M., Stone, G., Yoshinaga, A., Beedholm, K., and Madsen, P. T. (2009). "Feeding at a high pitch: Source parameters of narrow band, high-frequency clicks from echolocating off-shore hourglass dolphins and coastal Hector's dolphins," J. Acoust. Soc. Am. 125, 1783-1791.

Kyhn, L. A., Tougaard, J., Teilmann, J., Wahlberg, M., Jorgensen, P. B., and Bech, N. I. (2008). "Harbour porpoise (Phocoena phocoena) static acoustic monitoring: Laboratory detection thresholds of T-PODs are reflected in field sensitivity," J. Mar. Biol. Assoc. U.K. 88, 1085-1091.

Leeney, R. H., Berrow, S., McGrath, D., O'Brien, J., Cosgrove, R., and Godley, B. J. (2007). "Effects of pingers on the behaviour of bottlenose dolphins," J. Mar. Biol. Assoc. U.K. 87, 129-133.

Lund-Hansen, L. C., Laima, L. C., Mouritsen, K. N., Lam, Y., and Hai, A. (2002). "Effects of benthic diatoms, fluff layer, and sediment conditions on critical shear stress in a non-tidal coastal environment," J. Mar. Biol. Assoc. U.K. 82, 929-936.

Madsen, P. T., Kerr, I., and Payne, R. (2004). "Echolocation clicks of two free-ranging, oceanic delphinids with different food preferences: False killer whales Pseudorca crassidens and Risso's dolphins Grampus griseus," J. Exp. Biol. 207, 1811-1823.

Madsen, P. T., and Wahlberg, M. (2007). "Recording and quantification of ultrasonic echolocation clicks from free-ranging toothed whales," DeepSea Res., Part I 54, 1421-1444.
Marques, T. A., Thomas, L., Ward, J., DiMarzio, N., and Tyack, P. L. (2009). "Estimating cetacean population density using fixed passive acoustic sensors: An example with Blaineville's beaked whales," J. Acoust. Soc. Am. 125, 1982-1994.

Miksis-Olds, J. L., and Miller, J. H. (2006). “Transmission loss in manatee habitats," J. Acoust. Soc. Am. 120, 2320-2327.

Mooney, T. A., Au, W. W. L., Nachtigall, P. E., and Trippel, E. A. (2007). "Acoustic and stiffness properties of gillnets as they relate to small cetacean bycatch," ICES J. Mar. Sci. 64, 1324-1332.

Mooney, T. A., Natchigall, P. E., and Au, W. W. L. (2004). "Target strength of a nylon monofilament and an acoustically enhanced gillnet: Predictions of biosonar detection ranges," Aquat. Mamm. 30, 220-226.

Ona, E. (2003). "An expanded target-strength relationship for herring," ICES J. Mar. Sci. 60, 493-499.

Paskevich, V. F., Poppe, L. J., Hastings, M. E., and Hathaway, J. C. (2001). "Sea floor photography from the continental margin program: A pictorial survey of benthic character and habitats along the U.S. east coast," Open File Report 01-154, United States Geological Survey, Woods Hole, MA.

Philpott, E., Englund, A., Ingram, S., and Rogan, E. (2007). "Using T-PODs to investigate the echolocation of coastal bottlenose dolphins," J. Mar. Biol. Assoc. U.K. 87, 11-17.

Poppe, L. J., Williams, S. J., and Paskevich, V. F. (2005). "U.S.G.S. Eastcoast sediment analysis: Procedures, database and G.I.S. data," Open File Report No. 05-1001, United States Geological Survey, Woods Hole, MA. Porter, M. B., and Bucker, H. P. (1987). "Gaussian beam tracing for computing ocean acoustic fields," J. Acoust. Soc. Am. 82, 1349-1359.

Røy, H., Huettel, M., and Jørgensen, B. B. (2005). "The influence of topography on the functional exchange surface of marine soft sediments, assessed from sediment topography measured in situ," Limnol. Oceanogr. 50, 106-112

Stafford, K. M., Mellinger, D. K., Moore, S. E., and Fox, C. G. (2007). "Seasonal variability and detection range modeling of baleen whale calls in the Gulf of Alaska, 1999-2002," J. Acoust. Soc. Am. 122, 3378-3390.

Thomsen, F., van Elk, N., Brock, V., and Piper, W. (2005). "On the performance of automated porpoise-click-detectors in experiments with captive harbor porpoises (Phocoena phocoena) (L)," J. Acoust. Soc. Am. 118, 37-40.

Tindle, C. T., Deane, G. B., and Preisig, J. C. (2009). "Reflection of underwater sound from surface waves," J. Acoust. Soc. Am. 125, 66-72.

Todd, V. L. G., Pearse, W. D., Tregenza, N. C., Lepper, P. A., and Todd, I. B. (2009). "Diel echolocation activity of harbour porpoises (Phocoena phocoena) around North Sea offshore gas installations," ICES J. Mar. Sci. 66, 734-745.

Verfuss, U. K., Honnef, C. G., Meding, A., Dahne, M., Mundry, R., and Benke, H. (2007). "Geographical and seasonal variation of harbour porpoise (Phocoena phocoena) presence in the German Baltic Sea revealed by passive acoustic monitoring," J. Mar. Biol. Assoc. U.K. 87, 165-176.

Villadsgaard, A., Wahlberg, M., and Tougaard, J. (2007). "Echolocation signals of wild harbour porpoises, Phocoena phocoena," J. Exp. Biol. 210, 56-64.

Wilson, M. A., Farwell, R. W., and Stanic, S. (1994). "High-frequency propagation statistics in a shallow water environment," in OCEANS ' 94 Proceedings (IEEE, Brest, France), pp. 261-265.

Zimmer, W. M. X., Harwood, J., Tyack, P. L., Johnson, M. P., and Madsen, P. T. (2008). "Passive acoustic detection of deep-diving beaked whales," J. Acoust. Soc. Am. 124, 2823-2832. 